\title{
Evaluation of a Bicycle Helmet Safety Program for Children
}

\author{
Michael D. Cusimano, Ahmed Faress, Wilson P. Luong, Sally Lockhart, \\ Khizer Amin, Rhonda J. Garland, Kelly Russell
}

\begin{abstract}
Background: Helmets have been shown to decrease the risk of brain injury; however, helmets must be worn correctly and fit well in order to be effective. The objective of this study is to determine whether kindergarten-aged children could learn and retain appropriate helmet wearing technique through an educational bicycle safety program. Methods: Retrospective analysis of scores in questionnaires administered before and after an educational intervention to kindergarten students four to six years of age. The study took place in Prince Edward Island, Canada. A Wilcoxon Sign-Rank Test was used to determine if there was a significant overall increase in knowledge; McNemar chi-square tests were used to determine if there was an increase in knowledge for individual questions. Results: There was significant improvement in pre-test to immediate post-tests scores and pre-test to delay post-test scores when the results were stratified by age, sex, bike riding status, and helmet wearing status ( $\mathrm{p}<0.001$ for all comparisons). In particular, correct responses for the questions regarding appropriate helmet distances from the eyes increased from $38.9 \%$ in the pre-test to above $90 \%$ in the post-tests $(\mathrm{p}<0.001)$. Correct responses for the question pertaining to appropriate fitting of helmet straps increased from $71.7 \%$ pre-test to above $90 \%$ in the post-tests $(\mathrm{p}<0.001)$. Conclusions: There was improved knowledge of appropriate helmet-wearing technique among kindergarten-aged children as a result of the educational intervention, and knowledge gains were retained for at least one month.
\end{abstract}

RÉSUMÉ: Port du casque à vélo chez les enfants - évaluation d'un programme de sécurité. Contexte : Il a été démontré que le port d'un casque diminue le risque de traumatisme crânien ; cependant le casque doit être porté correctement et être bien ajusté pour être efficace. Le but de cette étude était de déterminer si des enfants en âge de fréquenter la maternelle pouvaient apprendre la bonne technique du port d'un casque enseignée dans le cadre d'un programme d'enseignement de la sécurité à vélo et s'ils pouvaient s'en souvenir. Méthode : Nous avons effectué une analyse des scores obtenus lors de questionnaires administrés avant et après une intervention éducative à des élèves de la maternelle âgés de 4 à 6 ans. L'étude a été réalisée à l'Ile du Prince-Édouard, au Canada. Nous avons utilisé le test de rang de Wilcoxon pour déterminer s'il y avait eu augmentation globale des connaissances et des tests du $\chi 2$ de McNemar pour déterminer s'il y avait eu augmentation des connaissances pour chaque question. Résultats : Nous avons constaté une amélioration significative entre les scores avant et immédiatement après le programme d'enseignement et également entre les scores avant l'enseignement et plus tardivement après l'enseignement, quand les résultats étaient stratifiés par âge, par sexe, selon que l'enfant allait ou non à vélo et selon que l'enfant portait ou non un casque ( $\mathrm{p}<0,001$ pour toutes les comparaisons). Les réponses correctes aux questions sur la distance adéquate entre le casque et les yeux augmentait de 38,9\% lors du pré-test à au-delà de $90 \%$ lors des post tests $(\mathrm{p}<0,001)$. Les bonnes réponses aux questions concernant l'ajustement adéquat des courroies du casque augmentaient de $71,7 \%$ lors du pré-test à plus de $90 \%$ lors des post tests $(\mathrm{p}<0,001$ ). Conclusions : Nous avons constaté une amélioration des connaissances sur la bonne technique du port du casque à vélo chez des enfants en âge de fréquenter la maternelle suite à une intervention éducative et les gains étaient maintenus après un mois.

Can J Neurol Sci. 2013; 40: 710-716

In the past two decades, there has been considerable growth in the popularity of bicycling in North America. ${ }^{1}$ In fact, more than 44 million individuals below 21 years of age in the United States ride a bicycle. ${ }^{2}$ Approximately 22 to $40 \%$ of cycling injuries in children are diagnosed as head injuries, and the majority of these children are not wearing helmets at the time of injury. ${ }^{3-5}$ Moreover, $60 \%$ of bicycle related fatalities are due to head injury. ${ }^{6}$ It is estimated that about 500 bicycle related fatalities and 151,000 non-fatal head injuries could be prevented each year in the United States alone if every cyclist wore a helmet. ${ }^{6}$ Thus, if helmets are worn by every rider, approximately one non-fatal head injury could be prevented every four seconds, and one death every day. ${ }^{6}$

Bicycle helmets have been shown to decrease the risk of head, brain and severe brain injury by $63-88 \% .^{7}$ However, helmets need to be worn correctly in order to be effective in reducing both morbidity and mortality. ${ }^{8}$ The risk of head injury is almost twice as high among riders with poor helmet fit compared with those who report excellent helmet fit. ${ }^{9}$ Children are particularly at risk since they are 3.9 times more likely than adults to utilize their helmet incorrectly. ${ }^{10}$

Thompson et al. states that for bicycle safety programs to be effective in preventing head injury, several behaviors must be

From the Injury Prevention Research Office, Keenan Research Centre (MDC, AF, WPL, KA, RJG, KR), Li Ka Shing Knowledge Institute, St Michael's Hospital, Toronto, Ontario; Spectrum Solutions (SL), Coleman, Prince Edward Island, Canada. Received March 18, 2013. Final Revisions Submitted March 27, 2013. Correspondence to: Michael D. Cusimano, Injury Prevention Research Office, St. Michael's Hospital, 30 Bond Street, Toronto, Ontario, M5B 1W8, Canada.

Email: injuryprevention@smh.ca. 
positively influenced, including correct and consistent helmet wearing. ${ }^{11}$ Moreover, previous research suggests that promoting bicycle helmet use significantly decreases the risk of head injury, particularly amongst younger children. ${ }^{12}$ Five notable educational programs in Canada, ${ }^{12,13}$ USA,${ }^{14}$ Australia, ${ }^{15}$ and Sweden ${ }^{16}$ have documented success in increasing the voluntary use of bicycle helmets. Such educational programs have often included instruction on bicycle rules of the road; however, no study has evaluated children's knowledge of correct bicycle helmet use.

In this study, we sought to determine whether kindergartenaged children (four to six years of age) could learn and successfully retain knowledge regarding the proper technique of wearing a bicycle helmet. Given that $7.4 \%$ of bicycle injuries occur in individuals five years of age or younger, ${ }^{5}$ we aimed our intervention towards as young an age group as possible. Hence, we sought to test our program in kindergarten-aged children, who are generally the youngest students in a school. Successful knowledge retention and positive behavioral change with regards to safety awareness has been reported in kindergartenaged children participating in simulation games, such as roleplaying and modeling. ${ }^{17}$

\section{METHODS}

\section{Intervention}

Eight hundred seventy-two children ranging from four to six years of age participated in the Prince Edward Island (PEI) ThinkFirst Hard Heads Program, a structured educational bicycle safety program, between April 2006 and June 2009. The program was first developed in 2004 when modifications were made to the Think First Kindergarten Wonderers Curriculum. In 2005-2006, initial curriculum and evaluation materials were pilot-tested with 150 students in seven kindergarten classrooms. The final curriculum, conducted in 24 kindergarten classes in PEI, Canada, consisted of approximately two 30-60 minute classroom lessons administered by the kindergarten teacher. The curriculum provided teachers with material that emphasized the importance of protecting the brain and spinal cord, demonstrated how to properly wear a helmet, and explained the value of bicycle helmets in protecting the brain. The students were taught the '2-V-1 rule' for correct helmet fitting: two fingers between the helmet and eyebrows, a V formed by the helmet straps under the ears, and one finger between the strap and chin. Two authors (SL, RG) taught kindergarten teachers how to deliver the program and administer evaluation materials. All curriculum materials were provided free of charge and available in English only. The curriculum was delivered through direct discussions with children, a variety of educational songs, educational games ("Brain Game"), and activities and props (Jell-O brain and egg helmet drop) that supplemented lessons by allowing children to actively participate and utilize their senses of touch, vision, and sight. Parents and caregivers were also provided with learning materials so as to reinforce the children's curriculum and promote discussion in the home.

\section{Evaluation}

Students were given an 11-item questionnaire as a pre-test (See Appendix A) immediately before the educational program and two identical post-tests, one immediately after and another one month after program completion. The questionnaire was divided into two sections: multiple choice questions and yes/no questions. During the multiple choice section, teachers read aloud the question and students were instructed to circle the correct answer. Students were informed that there was only one correct answer per question and teachers could repeat the questions as necessary. For each yes/no question, the script was read aloud and the students were asked to circle the happy face if the answer to the question was "Yes" and circle the sad face if the answer to the question was "No". In addition to the multiple choice and yes/no questions, two questions were included that asked if the child rode a bike or wore a helmet. A practical fitting test was developed to determine whether children could properly put on a helmet. However, after conducting the practical fitting test with three classrooms, it became apparent that such a test was not feasible with the available resources and was therefore discontinued.

\section{Statistical Analysis}

Demographic characteristics were tabulated and presented as proportions. Given the repeated nature of the data, the analysis was restricted to the children who completed all three tests. Due to the skewed nature of the data, the median and interquartile range of tests scores were reported. A Wilcoxon Sign-Rank test was used to ascertain if there was a significant increase in knowledge among the children. To determine whether there was an increase in knowledge for each question, a McNemar chisquare test was performed among the children who completed both tests (pre-test vs immediate; pre-test vs delay; immediate vs delay). A p-value of less than 0.05 was used to indicate statistical significance. Cronbach's alpha was calculated to determine how well the questions in the survey were correlated. A Kappa analysis was used to compare immediate post-test and delay post-test responses to indicate reliability of the responses by measuring chance corrected proportional agreement. All statistical analyses were performed using STATA 12.

\section{Ethics}

Ethical approval was granted by St Michael's Hospital, Toronto, Ontario, Canada.

\section{RESUlts}

Of the 872 children who participated, $53.5 \%$ were male and $40.7 \%$ were five years of age or younger. $76.6 \%$ of children identified themselves as bike riders for all three surveys and $77.8 \%$ always wore helmets. In total, 603 children (69.2\%) completed all three surveys, $197(22.6 \%)$ completed two surveys, and $72(8.3 \%)$ completed only one.

Among the $69 \%$ of children who completed all three surveys, there was significant improvement in bicycle helmet knowledge immediately after and one month after completing the educational bicycle helmet program (Table 1). There was significant improvement in pre-test to immediate post-test scores and pre-test to delay post-test scores when the results were independently stratified by age, sex, bike riding status and helmet wearing status. For all comparisons, the p-value was $<0.001$. When comparing immediate post-test to delay post-test 
Table 1: Median test scores (with IQR) for kindergarten students who completed all three tests

\begin{tabular}{l|l|l|l|l}
\hline & & Pre-test & Immediate Post-test & Delay Post-test \\
\hline & $\mathrm{N}$ & Median (IQR) & Median (IQR) & Median (IQR) \\
\hline Total & 603 & $6(5,8)$ & $7(6,10)$ & $7(7,10)$ \\
\hline Males & 335 & $6(5,8)$ & $8(7,10)$ & $9(7,10)$ \\
\hline Females & 268 & $6(5,8)$ & $7(6,10)$ & $7(6,10)$ \\
\hline Age $\leq 5$ & 296 & $6(5,7)$ & $7(6,10)$ & $7(6,10)$ \\
\hline Age $>5$ & 377 & $7(5,9)$ & $9(7,10)$ & $9(7,11)$ \\
\hline Rode a bike & 484 & $7(5,8)$ & $7(6,10)$ & $7(7,11)$ \\
\hline Did not ride a bike & 60 & $5(4,6.75)$ & $7(6,9)$ & $6(6,9)$ \\
\hline Wore a helmet & 508 & $6(5,8)$ & $7(7,10)$ & $7(7,11)$ \\
\hline Did not wear a helmet & 37 & $5(4,7)$ & $6(5,9.5)$ & $6(6,9.5)$ \\
\hline
\end{tabular}

helmets had significant improvement in knowledge for all questions when comparing pre-test and immediate post-test responses. Those who indicated they did not wear helmets had significant improvement for questions about helmet fitting, appropriate helmet distance from the eyes, appropriate fitting of helmet straps, and adult helmet use. When comparing pre-test with delay post-test responses, there was significant improvement in all questions except for the question about PEI's helmet law among children who wore helmets and significant improvement for all multiple choice questions (the first six questions) and the question about PEI's helmet law among non-helmet wearers. Multiple choice questions all had response rates above 93\%. Aside from the question about PEI's helmet law, response rates for scores, there was significant improvement for all children $(\mathrm{p}=0.030$, males $(\mathrm{p}=0.02)$, older children $(\mathrm{p}=0.01)$, bike riders $(\mathrm{p}<0.001)$, or helmet wearers $(\mathrm{p}=0.001)$.

Table 2 provides the proportion of children who correctly answered each question. There was a significant increase in knowledge from pre-test to immediate post-test for all questions $(\mathrm{p}<0.002)$ and the greatest increase in knowledge occurred for question 4 about appropriate helmet distance from the eyebrows (51.8\%) and question 5 about appropriate fitting of helmet straps (19.9\%). With the exception of question 11 asking about PEI's bike helmet law $(\mathrm{p}<0.48)$, there was a significant increase in pre-test to delay post-test knowledge $(\mathrm{p}<0.001)$. When comparing immediate post-test to delay post-test, there was a significant increase in the proportion of children answering correctly for questions about how a helmet fit properly around the head, what constituted a safe helmet, and what size a helmet was supposed to be $(\mathrm{p}<0.03)$; there was a significant decline in correct answers for the question about PEI's helmet law $(\mathrm{p}<0.001)$.

Comparing pre-test and immediate post-test responses, significant improvement $(\mathrm{p}<0.05)$ was demonstrated for all questions except for PEI's helmet law question amongst bike riders, whereas non-riders failed to demonstrate significant improvement for questions about the appropriate fitting of helmet straps, wearing hats under a helmet, having a ponytail under a helmet, and the appropriate size of helmets. The pattern was identical for pre-test versus delay post-test among bike riders. However, among non-bike riders, there was significant improvement in the proportion of children answering the question about appropriate fitting of helmet straps correctly and no significant difference for questions about adult helmet use, hats under a helmet, ponytails under a helmet, appropriate size of helmet, and PEI's helmet law. Children who reported wearing yes/no questions ranged from $48-50 \%$.

After correcting for change, there was substantial agreement between immediate and delayed post-test responses for the questions about wearing hats under helmets, ponytails under the helmet, and regarding cracks/dents on the helmet; there was moderate agreement for questions about how a helmet fit around
Table 2: Percentage of kindergarten students who answered each question correctly among students completing all tests

\begin{tabular}{l|c|c|c}
\hline Question & Pre-test (\%) & Immediate Post-test (\%) & Delay Post-test (\%) \\
\hline $1-$ helmet fit & 62.5 & 81.1 & 86.2 \\
\hline $2-$ chin strap & 89.6 & 94.8 & 96.8 \\
\hline $3-$ safe helmet & 84.0 & 92.7 & 95.7 \\
\hline $4-$ distance from eyes & 38.9 & 90.7 & 91.7 \\
\hline $5-$ straps around ears & 71.7 & 91.6 & 93.1 \\
\hline 6 - adult helmet use & 89.0 & 95.6 & 96.1 \\
\hline $7-$ no hat under helmet & 67.6 & 88.5 & 91.2 \\
\hline $8-$ no ponytail under helmet & 70.2 & 88.3 & 90.2 \\
\hline $9-$ no cracks/dents on helmet & 75.3 & 89.0 & 78.6 \\
\hline $10-$ proper size helmet & 55.8 & 69.0 & 86.9 \\
\hline $11-$ mandatory helmet law in PEI & 87.6 & 92.0 & \\
\hline
\end{tabular}

the head, what constituted a safe helmet, appropriate distancing of helmet from the eyes, and proper size of helmets (Table 3) ${ }^{18,19}$. In general, there was higher agreement for the yes/no questions than the multiple choice questions.

The Cronbach's alpha varied by the timing of the test and ranged from 0.45 (delayed post-test) to 0.63 (immediate posttest).

\section{DISCUSSION}

A structured bicycle safety program was effective in improving the knowledge of safe and effective helmet use and fitting technique among kindergarten-aged children. Furthermore, we found that this knowledge was retained for at least one month. A similar study examined the effectiveness of a structured bicycle safety program at improving children's 
Table 3: Summary of agreement by each question for immediate and delay post-test

\begin{tabular}{l|c|c|c|l}
\hline Question & Agreement (\%) & $\begin{array}{l}\text { Expected } \\
\text { Agreement }(\%)\end{array}$ & Kappa & Interpretation* \\
\hline $1-$ helmet fit & 84.9 & 72.0 & 0.46 & Moderate \\
\hline $2-$ chin strap & 94.5 & 92.0 & 0.32 & Fair \\
\hline $3-$ safe helmet & 94.7 & 88.1 & 0.56 & Moderate \\
\hline $4-$ distance from eyes & 90.6 & 83.8 & 0.42 & Moderate \\
\hline $5-$ straps around ears & 89.0 & 84.9 & 0.27 & Fair \\
\hline $6-$ adult helmet use & 95.2 & 92.3 & 0.38 & Fair \\
\hline $7-$ no hat under helmet & 96.2 & 86.0 & 0.73 & Substantial \\
\hline $8-$ no ponytail under helmet & 95.2 & 87.1 & 0.63 & Substantial \\
\hline $9-$ no cracks/dents on helmet & 95.6 & 85.4 & 0.70 & Substantial \\
\hline $10-$ proper size helmet & 84.7 & 67.2 & 0.53 & Moderate \\
\hline $11-$ mandatory helmet law in PEI & 89.3 & 80.5 & 0.45 & Moderate \\
\hline
\end{tabular}

*According to Cohen's interpretation ${ }^{18,19}$

knowledge of bicycle safety including the proper use of bicycle helmets. ${ }^{20}$ The program, consisting of a videotape presentation and a structured discussion of bicycle safety rules, was presented to four classes of elementary school children from grades 1 to 3 and there was significant improvement in retained knowledge of safe bicycle riding practices and helmet use.

On the pre-test, only $38.9 \%$ of students correctly identified that the front of the helmet should be two finger-widths away from the eyebrows. More than $90 \%$ of the students understood this concept following completion of the program. In addition, the percentage of students who correctly identified that the helmet straps should form a V-shape under the ears significantly increased from $71.6 \%$ to more than $90 \%$. The implications of the large increase in correct responses to these questions is two-fold; firstly, that a large number of kindergarten-aged individuals are not aware of appropriate helmet-wearing technique with respect to the helmet being two finger-widths away from the eyebrows and helmet straps forming a V-shape. This location of the helmet low on the forehead is particularly important for proper head protection in the event of a frontal fall. ${ }^{8}$ Too high a helmet is a very common mistake in positioning helmets and is crucial to improving the safety of helmet wearing. 8,9 Secondly, understanding and successful retention of these skills in children is readily attainable. Therefore, these techniques constitute an easily rectified gap in knowledge, and future interventions can focus on educating young children on these two techniques.

Overall, significant improvement was demonstrated from all pre-test to immediate post-test questions. When comparing pretest with delayed post-test responses, there was significant improvement for all questions with the exception of the question regarding PEI's helmet law. However, this could be partially attributed to baseline knowledge: $87.6 \%$ of students knew before the intervention that helmet use was required by law and therefore the margin for improvement was limited.

The low response rate for yes/no questions (questions 7-10) was an unexpected outcome of the study. Although the limited attention span of the children may have been a contributing factor, the fact that the sixth question (a multiple choice question) was answered by $97.8 \%$ of students, while the seventh one (a yes/no question) was only answered by $49.1 \%$ of students suggests that question format was a factor affecting the ability of children to respond. Although both the yes/no and multiple choice questions in our study recruited recognition memory, it is likely that each question type probed different aspects of this memory. Multiple choice questions predominantly relied on "familiarity" as the children were required to select the most familiar picture out of the three presented. All of the yes/no questions (with the exception of the last question regarding PEI's helmet law), however, depended primarily on "recollection" as the children had to recall whether they had been previously presented with the specific picture under question. Rugg and Yonelinas explain that recollection is a slow process, which requires more attention than familiarity during both encoding and retrieval. ${ }^{21}$ Hence, the difference in response rates seen between yes/no and multiple choice questions can likely be attributed to the format of the questions. Questions relying on recollection may have been too difficult for some of children to attempt.

Additionally, a study on language comprehension among school-age children found that the complexity of verbal instruction provided by a teacher and the amount of time provided to understand that instruction were crucial determinants of a student's comprehension..$^{22}$ The understanding of complex language commands among elementary school students was found to be lowest in kindergarten students. ${ }^{22}$ Kindergarten students also demonstrated the slowest speed of language comprehension..$^{22}$ These factors may have contributed to some of the low response rates seen with some questions on the tests among the kindergarten students who participated in our study.

Children who reported that they rode a bicycle or wore a helmet had significant improvement on more questions than their counterparts. This may be because children who ride a bicycle may be more likely to retain the taught information since it would be relevant to them. These children will also have increased opportunities to apply the safety knowledge gained from a bicycle safety program, such as Hard Heads. Finally, the majority of children classified themselves as bike riders and the smaller sample size for children who do not ride a bike or wear a helmet may have precluded statistical significance. 
Thompson et al. suggest that in order for a bicycle helmet promotion program to effect change, several behaviors must be influenced including helmet purchase, correct helmet wearing, and consistent helmet wearing. ${ }^{11}$ This requires a multifaceted approach. The Hard Heads program incorporated a range of songs, demonstrations, and activities, which together addressed the different behaviours listed above. We thought that effectively preventing head injury in young children may be facilitated by influencing parental behaviour such as helmet purchasing and encouragement of its use. To that end, a take-home information package for parents was incorporated into our curriculum.

While the ultimate goal was to induce behavioural change, a key limitation of this study was the absence of a behavioural assessment component. Although we attempted to incorporate a helmet fitting practical exam, this was not possible due to the logistical challenges. For example, some students had helmets while others did not, and adjusting the helmets for children who did not have helmets was beyond the limits of our study. Some teachers raised a concern regarding the passing of head lice by sharing helmets. Also, we did not have the funding to support practical helmet fit testing. The ability to evaluate behavioural change may have provided additional support to the effectiveness of the program and could have also provided valuable feedback in terms of the program's improvement. Accordingly, future studies should focus on assessing whether changes in knowledge about appropriate helmet use can translate into discernible behavioural changes. The limitations we encountered could be addressed while designing future studies.

A second limitation was the misclassification of bike riding and helmet wearing status. For instance, there were more children who indicated that they wore a helmet than there were children who reported riding a bicycle. It could be that children misconstrued the questions about helmets as meaning any sort of helmet, not just bicycle helmets.

\section{CONClusions}

There was improved knowledge of appropriate helmetwearing techniques among kindergarten-aged children who participated in the educational program and this knowledge was retained for at least one month. Future interventions can particularly focus on teaching children to wear a helmet twofinger widths above the eyebrows, and to form a V-shape with the helmet straps. Further research in this area should place emphasis on assessing behavioral change associated with changes in knowledge and the roles of caregivers in enhancing optimum behavior. Longitudinal studies should determine the sustainability of safety behavioral changes and if injuries are reduced.

\section{ACKNOWLEDGEMENTS}

Funding for this study was provided by the Prince Edward Island Partners for Children Fund, and Canadian Institutes of Health Research Strategic Team Grant in Applied Injury Research \# TIR-103946.

\section{REFERENCES}

1. Pucher J, Buehler R, Seinen M. Bicycling renaissance in North America? An update and re-appraisal of cycling trends and policies. Transportation Research Part A. 2011;45:451-75.

2. Rodgers GB. Bicycle and bicycle helmet use patterns in the United States in 1998. J Safety Research. 2000;31:149-58.

3. Selbst SM, Alexander D, Ruddy R. Bicycle-related injuries. Am J Dis Child. 1987;141(2):140-4.

4. Linn S, Smith D, Sheps S. Epidemiology of bicycle injury, head injury, and helmet use among children in British Columbia: a five year descriptive study. Canadian Hospitals Injury, Reporting and Prevention Program (CHIRPP). Inj Prev. 1998;4(2):122-5.

5. Rivara FP, Thompson DC, Thompson RS. Epidemiology of bicycle injuries and risk factors for serious injury. Inj Prev. 1997;3: $110-4$.

6. Sacks JJ, Holmgreen P, Smith SM, Sosin DM. Bicycle-associated head injuries and deaths in the United States from 1984 through 1988. How many are preventable? JAMA. 1991;266(21): 3016-8.

7. Thompson DC, Rivara FP, Thompson RS. Helmets for preventing head and facial injuries in bicyclists. Cochrane Database Syst Rev. 2000;2:CD001855.

8. Lee RS, Hagel BE, Karkhaneh M, Rowe BH. A systematic review of correct bicycle helmet use: how varying definitions and study quality influence the results. Inj Prev. 2009;15(2):125-31.

9. Rivara FP, Astley SJ, Clarren SK, Thompson DC, Thompson RS. Fit of bicycle safety helmets and risk of head injuries in children. Inj Prev. 1999;5(3):194-7.

10. Hagel BE, Lee RS, Karkhaneh M, Voaklander D, Rowe BH. Factors associated with incorrect bicycle helmet use. Inj Prev. 2010;16:178-84

11. Thompson NJ, Sleet D, Sacks JJ. Increasing the use of bicycle helmets: lessons from behavioral science. Patient Educ Couns. 2002;46(3):191-7.

12. Farley C, Haddad S, Brown B. The effects of a 4-year program promoting bicycle helmet use among children in Quebec. Am J Public Health. 1996;86(1):46-51.

13. Parkin PC, Spence LJ, Hu X, Kranz KE, Shortt LG, Wesson DE. Evaluation of a promotional strategy to increase bicycle helmet use by children. Pediatrics 1993;91(4):772-7.

14. DiGuiseppi CG, Rivara FP, Koepsell TD, Polissar L. Bicycle helmet use by children. Evaluation of a community-wide helmet campaign. JAMA. 1989;262(16):2256-61.

15. Wood T, Milne P. Head injuries to pedal cyclists and the promotion of helmet use in Victoria, Australia. Accid Anal Prev. 1988;20 (3): $177-85$.

16. Ekman R, Schelp L, Welander G, Svanström L. Can a combination of local, regional and national information substantially increase bicycle-helmet wearing and reduce injuries? Experiences from Sweden. Accid Anal Prev. 1997;229(3):321-8.

17. Renaud L, Suissa S. Evaluation of the efficacy of simulation games in traffic safety education of kindergarten children. Am J Public Health. 1989; 79(3):307-9.

18. Cohen J. A coefficient of agreement for nominal scales. Educ Psychol Meas. 1960;20:37-46.

19. Landis JR, Koch GG. The measurement of observer agreement for categorical data. Biometrics. 1977;33(1):159-74.

20. Nagel RW, Hankenhof BJ, Kimmel SR, Saxe JM. Educating grade school children using a structured bicycle safety program. J Trauma. 2003;55(5):920-3.

21. Rugg MD, Yonelinas AP. Human recognition memory: a cognitive neuroscience perspective. Trends Cogn Sci. 2003;7(7):313-9.

22. Wassenberg R, Hurks PP, Hendriksen JG, et al. Age-related improvement in complex language comprehension: results of a cross-sectional study with 361 children aged 5 to 15. J Clin Exp Neuropsychol. 2008;30(4):435-48. 


\section{APpendix A}

Multiple Choice Questions

1.
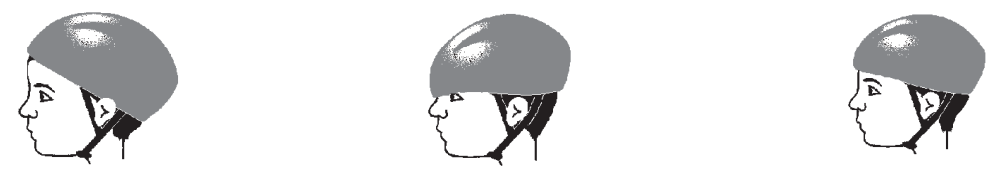

"Circle the picture that you think is the right way to have a helmet on your head."

2.
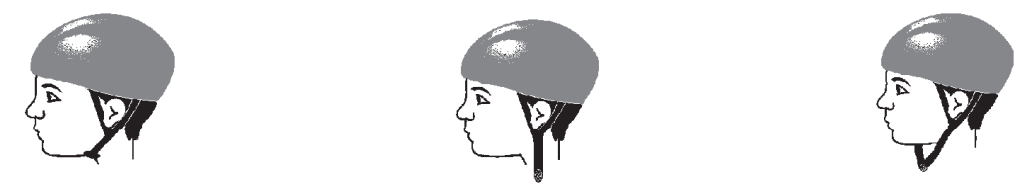

"Circle the picture that looks like the right way to wear the strap under your chin."

3.
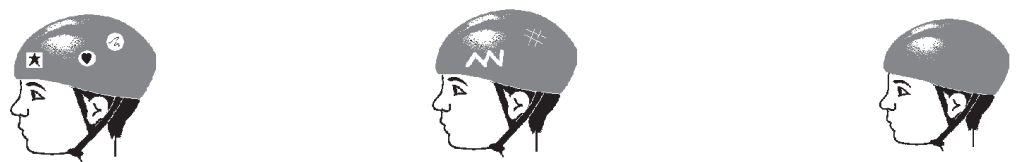

"Circle the picture that looks like a helmet that is the safest."

4.
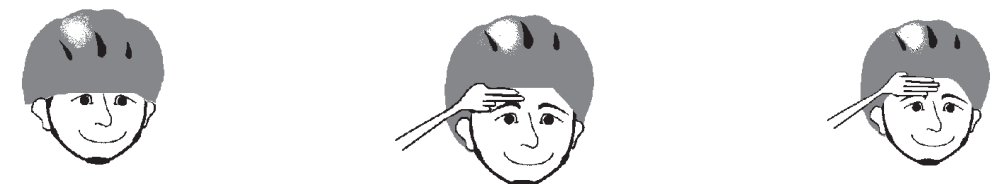

"Circle the picture that snows tne rignt number of fingers that the helmet should be away from your eyes."

5.
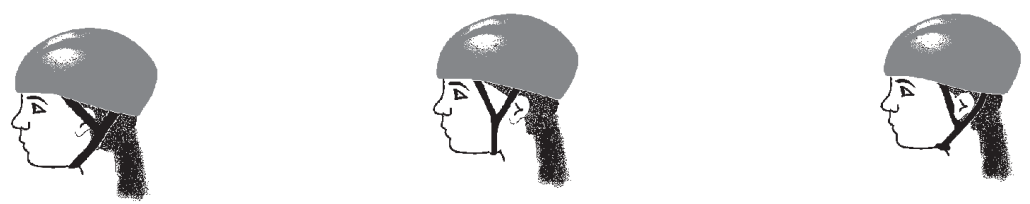

"Circle the picture that looks like the right way the straps should be on the side of your head."

6.
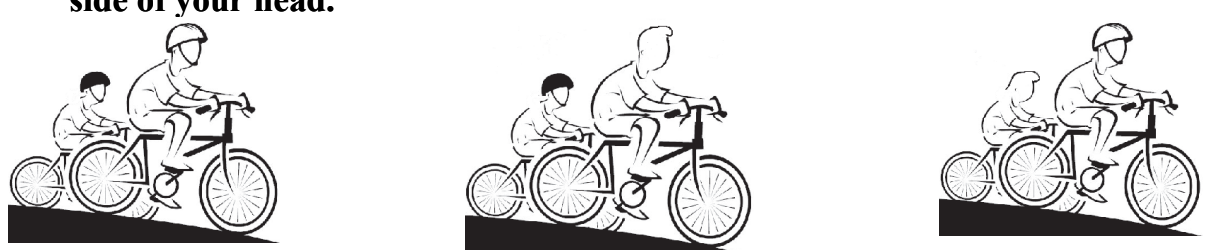

"Circle the picture that looks like the right way you and your parents should ride your bikes."

Yes/ No Questions

7.

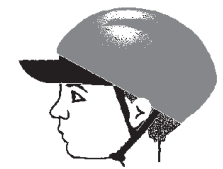

(:)

Yes
(2)

No

"Circle the happy face if you think that this is the right way to wear a helmet, circle the sad face if you think this is the wrong way to wear a helmet." 
8.

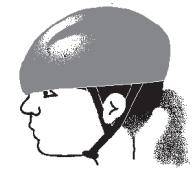

$$
\begin{array}{ll}
\text { Yes } & \text { (:) } \\
\text { Yo }
\end{array}
$$

"Circle the happy face if you think that this is the right way to wear a helmet, circle the sad face if you think this is the wrong way to wear a helmet."

9.
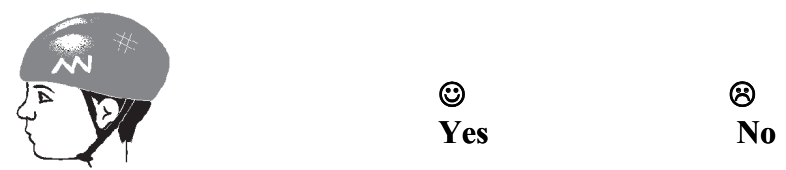

"Circle the happy face if you think that this is the right way to wear a helmet, circle the sad face if you think this is the wrong way to wear a helmet."

10.
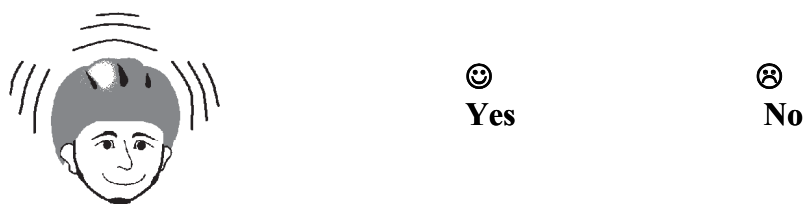

"Circle the happy face if you think that this is the right way to wear a helmet, circle the sad face if you think this is the wrong way to wear a helmet."

11.

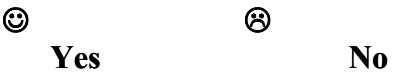

Circle the happy face if you think it is a law that you have to wear a helmet when you ride your bike. Circle the sad face if you think there is not a law."

12.
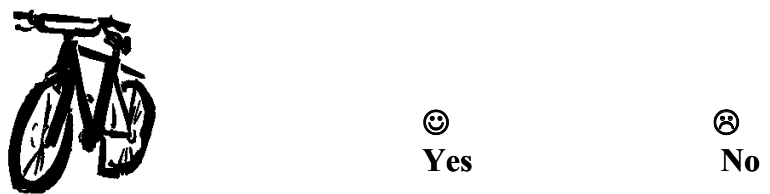

"Do you ride a bicycle?" "Circle the happy face if you ride a bike, or circle the sad face if you don't."

13.
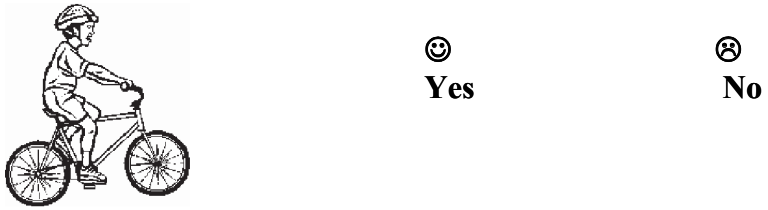

"Do you wear a helmet when riding a bicycle?" "Circle the happy face if you wear a helmet when you ride a bike, or circle the sad face if you don't." 